\title{
Single- and double-SSR primer combined analyses in rice
}

\author{
J. Ma, S.C. Guan, Z. Zhang and P.W. Wang \\ Biotechnology Center of Jilin Agricultural University, Changchun, China \\ Corresponding author: P.W. Wang \\ E-mail: winter0106@163.com
}

Genet. Mol. Res. 11 (2): 1032-1038 (2012)

Received January 12, 2012

Accepted March 22, 2012

Published April 27, 2012

DOI http://dx.doi.org/10.4238/2012.April.27.1

\begin{abstract}
Polymerase chain reaction (PCR) is the foundation of SSR molecular marker technology. We used sib rice varieties J518, XD1 and SD23 as experimental materials, selecting 30 pairs of SSR primers, including RM127, RM337 and RM5172, covering the rice genome, and performed single- and double-SSR primer combined analyses. We found that under the same PCR system and conditions, a single primer of the SSR primer pairs could amplify the same fragments as double primers do. The sequencing results demonstrated that some amplified fragments that we previously believed to come from double primers were actually produced by a single primer. The use of this kind of primer, such as the RM127 primer pair, for marker-assisted breeding will therefore be misleading. Additionally, using the same PCR system and conditions, some single primers that are part of SSR primer pairs can amplify many more specific fragments than double-SSR primers. For instance, in the case of the RM5172 primer pair, a single primer P1 amplified approximately three times the number of fragments as the double primer. This information can contribute to research on genetic diversity of species, understanding of genetic relationships and identification of germplasm resources. Accordingly, combined analyses of single- and double-primer amplification products not only can remove single-primer amplification fragments and false-positives from
\end{abstract}


double-primer amplification products in order to improve test accuracy, but also can facilitate research on genetic diversity, exploration of phylogenetic relationships and identification of germplasm resources. We define this method as "single- and double-SSR primer combined analyses".

Key words: SSR; PCR; False-positive exclusion; Single-primer PCR

\section{INTRODUCTION}

Single sequence repeats (SSR) molecular marker technology has been widely used in genetic mapping, research of genetic diversity, exploration of phylogenetic relations, and identification of germplasm resources in rice, soybean, and wheat (Brown-Guedira et al., 2000; Wei et al., 2004; Wen et al., 2008). Polymerase chain reaction (PCR) is the foundation of SSR molecular markers technology (Sayama et al., 2009; Liu et al., 2010); it relies on accurate amplification products. However, plant genomes are large and complex. During the PCR process with SSR primers used in pairs, a single primer likely amplifies fragments. This may result in fragment impurities and false-positives, which adversely affect subsequent selection. Our previous study has demonstrated that double-SSR primer amplification products in soybean contain false-positives or impure fragments that are produced by single-primer amplification (Ma et al., 2011).

We have now compared single- and double-primer amplification products amplified by 30 pairs of SSR primers in rice.

\section{MATERIAL AND METHODS}

\section{Material}

J518, XD1 and SD23 rice varieties were provided by the Agronomy College of Jilin Agricultural University. DNA Polymerase, dNTP mix, DNA Gel Extraction Kit, DNA Marker, and Genomic DNA Extraction Kit were purchased from TaKaRa (Dalian, China). Other biochemical reagents, including acrylamide, methylene acrylamide, boric acid, ethylenediaminetetraacetic acid (EDTA), sodium hydroxide $(\mathrm{NaOH})$, silver nitrate $\left(\mathrm{AgNO}_{3}\right)$, Tris (hydroxymethyl)aminomethane (Tris), urea, Tris base, ethidium bromide, agarose, yeast extract powder and tryptone, were supplied by AMRESCO (USA).

\section{SSR primers}

SSR primer pairs were randomly selected for 30 individual SSRs: RM6, RM10, RM13, RM17, RM21, RM22, RM24, RM38, RM71, RM72, RM80, RM127, RM161, RM166, RM206, RM219, RM224, RM246, RM248, RM261, RM276, RM337, RM423, RM438, RM538, RM583, RM590, RM5172, RM6358, and RM8270 (http://www.graingenes.org).

\section{PCR with single- and double-SSR primers for J518, XD1 and SD23 rice}

Total DNA was extracted from J518, XD1 and SD23 leaves using the Universal Ge- 
nomic DNA Extraction Kit, version 3.0, according to manufacturer instructions (TaKaRa). The genome DNA was quantified on the nucleic acid/protein detector and the PCR was run.

The reaction mixture for double-primer amplification of RM6 contained ( $10 \mu \mathrm{L}$ total) $1.0 \mu \mathrm{L} 10 \mathrm{X}$ buffer, $1.0 \mu \mathrm{L} 20 \mathrm{mM} \mathrm{MgCl}, 0.3 \mu \mathrm{L} 10 \mathrm{mM}$ for each dNTP, $1.0 \mu \mathrm{L} 20 \mu \mathrm{M}$ RM6 P1 and $\mathrm{P} 2$ primer, $1.0 \mu \mathrm{L}<1 \mu \mathrm{g}$ genomic DNA templates, $0.2 \mu \mathrm{L} 5 \mathrm{U} / \mu \mathrm{L}$ DNA polymerase, and $4.5 \mu \mathrm{L} \mathrm{ddH}_{2} \mathrm{O}$. The PCR amplification program included predenaturation at $94^{\circ} \mathrm{C}$ for 3 min; 35 cycles $\left(94^{\circ} \mathrm{C}\right.$ for $45 \mathrm{~s}, 55^{\circ} \mathrm{C}$ for $45 \mathrm{~s}$ and $72^{\circ} \mathrm{C}$ for $\left.50 \mathrm{~s}\right)$; extension at $72^{\circ} \mathrm{C}$ for $8 \mathrm{~min}$.

The reaction mixture for RM6 P1 single-primer amplification contained $(10 \mu \mathrm{L}$ total $)$ $1.0 \mu \mathrm{L} 10 \mathrm{X}$ buffer, $1.0 \mu \mathrm{L} 20 \mathrm{mM} \mathrm{MgCl}, 0.3 \mu \mathrm{L} 10 \mathrm{mM}$ for each dNTP, $1.0 \mu \mathrm{L} 20 \mu \mathrm{M}$ RM6 P1 primer, $1.0 \mu \mathrm{L}<1 \mu \mathrm{g}$ genomic DNA templates, $0.2 \mu \mathrm{L} 5 \mathrm{U} / \mu \mathrm{L}$ DNA polymerase, and 5.5 $\mu \mathrm{L} \mathrm{ddH}_{2} \mathrm{O}$. Cycling conditions were the same as with RM6 double-primer PCR. The reaction mixture and cycling conditions for RM6 P2 single-primer amplification were the same as for RM6 P1 single-primer PCR. The reaction mixture and cycling conditions for single- and double-primer amplification of other primers were the same as for RM6 PCR, except that the annealing temperature was empirically adjusted to the primers.

\section{SSR analyses of single- and double-primer amplification products}

Single- and double-primer amplification products for each pair of SSR primers were compared. Single- and double-primer amplification fragments at the same length were recycled and ligated with T-vector, followed by gene transfer and sequencing by Beijing SanboZhiyuan Company (China). Single-primer amplification polymorphism between different rice varieties was investigated.

\section{RESULTS}

\section{Comparison of single- and double-SSR primer amplification products}

The experiments compared single- and double-primer amplification products for 30 pairs of SSR primers in rice. For multiple SSR primers, double-primer amplification fragments and single-primer amplification fragments had the same length in bp. In the case of RM127 primers, the A and D fragments amplified by RM127 double primers in J518 rice had the same bp lengths as with the B and E fragments amplified by P2 single primer in J518 rice, respectively. The $\mathrm{C}$ fragment amplified by double primers in XD1 rice had the same bp length as the A fragment amplified by double primers in J518 rice (Figure 1).

We assume two likelihoods for double primers to amplify the A and D fragments: 1) $\mathrm{A}$ and $\mathrm{B}$, as well as $\mathrm{D}$ and $\mathrm{E}$, are the same fragments, which are $\mathrm{P} 2$ single-primer amplification fragments, or 2) A and D are impure fragments, that is, A (or D) fragment contains two types of amplification products. One part is $\mathrm{P} 1 / \mathrm{P} 2$ double-primer amplification products and the other type is P2 single-primer amplification fragments (B or E). Both parts have the same bp lengths, which cannot be separated by PAGE. Similarly, the C fragment may also have two likelihoods above.

By recycling the $\mathrm{A}, \mathrm{B}, \mathrm{D}$, and $\mathrm{E}$ fragments and sequencing, we found that the $\mathrm{A}$ and $\mathrm{B}$ fragments were the same sequences and the $\mathrm{D}$ and $\mathrm{E}$ fragments were the same sequences. These results demonstrated that in the case of rice double-SSR primer amplification products, 


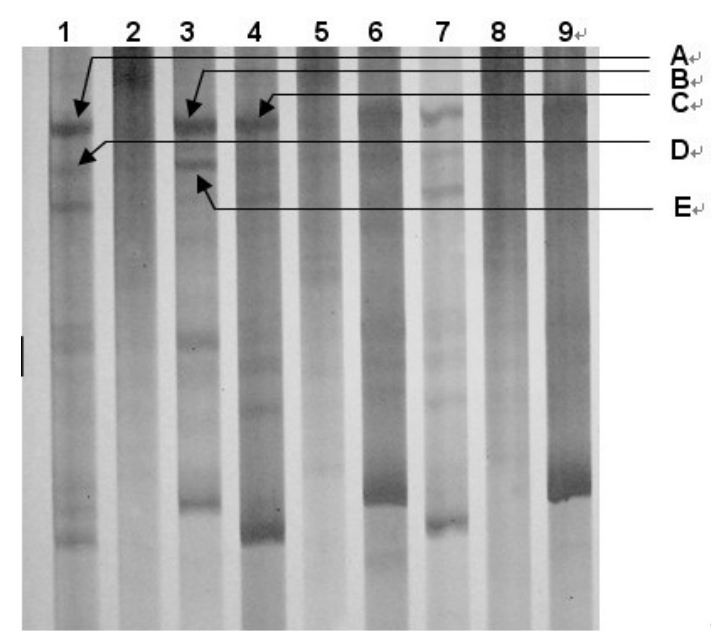

Figure 1. PCR amplification fragments (A-E) using RM127 single- and double-primers for J518, XD1 and SD23 rice. Lane 1 = using RM127 double-primer for J518; lane 2 = using P1 primer for J518; lane 3 = using P2 primer for J518; lane 4 = using RM127 double-primer for $\mathrm{XD} 1$; lane $5=$ using $\mathrm{P} 1$ primer for $\mathrm{XD} 1$; lane $6=$ using $\mathrm{P} 2$ primer for $\mathrm{XD} 1$; lane 7 = using RM127 double-primer for SD23; lane $8=$ using $\mathrm{P} 1$ primer for SD23; lane $9=$ using $\mathrm{P} 2$ primer for SD23.

some fragments were not double-primer amplification products, but rather they were singleprimer amplification products.

\section{Single- and double-SSR primer amplification product polymorphisms}

When compared 30 pairs of SSR single- and double-primer amplification products for exploring genetic diversity and evolutionary relationships and for identification of germplasm resources, we found that multiple SSR single-primer amplification products could provide more polymorphism information than double-primer amplification products. RM337 and RM5172 single primers and RM337 double primers amplified the B and $\mathrm{F}$ fragments in J518 and XD1 rice, respectively, and amplified the D and G fragments in SD23 rice. On this basis, J518 and XD1 rice were classified into one class and SD23 rice into another class. However, J518 and XD1 rice could not be discriminated only on the basis of double-primer amplification products. When RM337 single-primer amplification products were analyzed, we found no products for the RM337 single primer in XD1; the RM337 P1 single primer in J518 amplified three $\mathrm{H}$, I and J fragments and single primer P2 amplified three A, C and E fragments. Accordingly, J518 and XD1 rice could be further distinguished (Figure 2).

In analyses of RM5172 single-primer amplification products, RM5172 P1 and P2 single primers amplified multiple specific fragments in J518 and XD1 rice, respectively. The degree of polymorphism was higher than with the double-primer amplification. The RM5172 P1 single primer amplified six specific fragments (A, B, G, H, J, L, and Q) in J518 rice and four specific fragments $(\mathrm{C}, \mathrm{D}, \mathrm{I}$, and $\mathrm{P})$ in XD1 rice. RM5172 $\mathrm{P} 2$ single primer amplified two specific fragments ( $\mathrm{M}$ and $\mathrm{O}$ ) in J518 rice and four specific fragments (E, F, K, and N) in XD1 rice (Figure 3). 


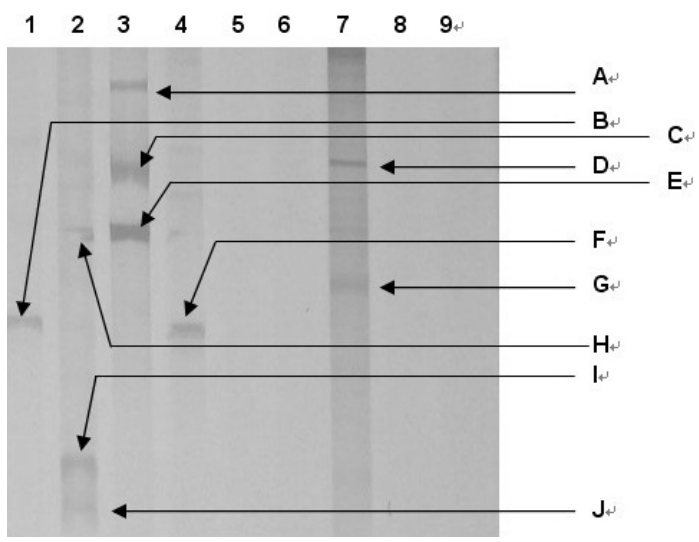

Figure 2. PCR amplification fragments (A-J) using RM337 single- and double-primers for J518, XD1 and SD23 rice. Lane 1 = using RM337 double-primer for J518; lane $2=$ using P1 primer for J518; lane 3 = using P2 primer for $\mathrm{J} 518$; lane 4 = using RM337 double-primer for XD1; lane $5=$ using P1 primer for XD1; lane $6=$ using $\mathrm{P} 2$ primer for $\mathrm{XD} 1$; lane 7 = using RM337 double-primer for SD23; lane $8=$ using $\mathrm{P} 1$ primer for SD23; lane 9 = using $\mathrm{P} 2$ primer for SD23.
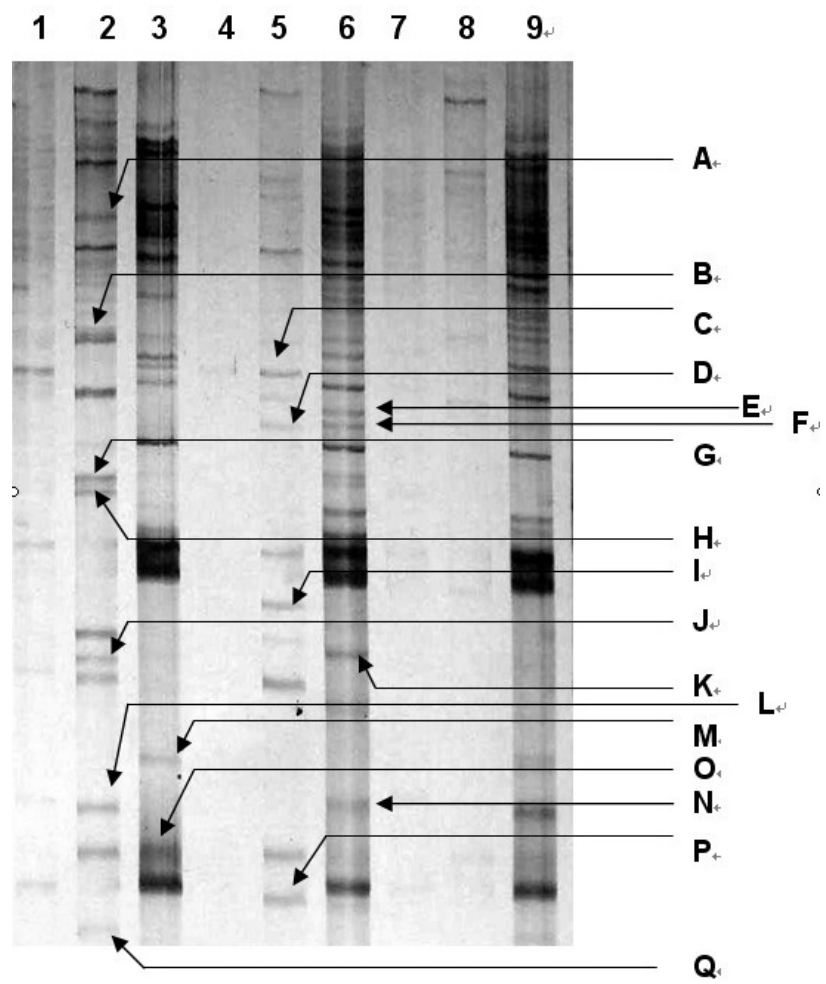

Figure 3. PCR amplification fragments (A-Q) using RM5172 single- and double-primers for J518, XD1 and SD23 rice. Lane 1 = using RM5172 double-primer for J518; lane $2=$ using P1 primer for J518; lane 3 = using P2 primer for J518; lane 4 = using RM5172 double-primer for XD1; lane $5=$ using $\mathrm{P} 1$ primer for $\mathrm{XD} 1$; lane $6=$ using $\mathrm{P} 2$ primer for $\mathrm{XD} 1$; lane 7 = using RM5172 double-primer for SD23; lane $8=$ using P1 primer for SD23; lane 9 = using P2 primer for SD23. 


\section{DISCUSSION}

PCR plays a significant role as the foundation of SSR molecular marker technology. Nonspecific amplifications and false-positives are the problems to be considered in research. Many factors can cause nonspecific amplifications; however, the plant genome is large and complex and thus a single primer likely amplifies nonspecific fragments and results in falsepositives even under strict conditions. This single-primer nonspecific amplification is generated under the same PCR systems and conditions as with double-primer amplification, so it is difficult to correct for this by optimizing PCR systems and conditions. This finding is consistent with the results studied in soybeans (Ma et al., 2011).

Fortunately, when consider molecular marker methods, such as RAPD or AP-PCR, we find that primers for RAPD or AP-PCR is not used in pairs; they are used singly (Welsh and McClelland, 1990; Williams et al., 1990; La Rosa et al., 2003). Similarly, we can use arbitrary single primer of each pair of SSR primers as primers for RAPD or AP-PCR. In our study, we found that combined analyses of single- and double-SSR primer amplification products can correct nonspecific single-primer amplification fragments, which are mixed in double-primer amplification fragments, and thus remove a portion of the false-positives. At the same time, single-primer amplification products can provide more polymorphism information, which has application values for research on genetic diversity, exploration of phylogenetic relations and identification of germplasm resources. RAPD or AP-PCR primers are random and arbitrary. Single- and double-SSR primer combined analyses are different from RAPD or AP-PCR, i.e., a single primer in SSR analyses is one of each pair of SSR primers, and a PCR system and conditions for double-primer amplification are required for a single primer.

\section{CONCLUSIONS}

In our study, single- and double-SSR primer PCRs were run under the same conditions. Combined analyses of single- and double-primer amplification products can remove single-primer-amplified false positives from double-primer amplification products and obtain more genetic diversity information. We define this method as "single- and double-SSR primer combined analyses". This method has important application values for research on genetic diversity, exploration of phylogenetic relations, identification of germplasm resources, and molecular marker-assisted breeding.

\section{ACKNOWLEDGMENTS}

Research supported by the National Natural Science Foundation of China (\#30971805) and the Young Scientists Foundation of JILIN Province in China (\#20100145).

\section{REFERENCES}

Brown-Guedira GL, Thompson JA, Nelson RL and Warburton ML (2000). Evaluation of genetic diversity of soybean introductions and North American ancestors using RAPD and SSR markers. Crop Sci. 40: 815-823.

La Rosa R, Angiolillo A, Guerrero C, Pellegrini M, et al. (2003). A first linkage map of olive (Olea europaea L.) cultivars using RAPD, AFLP, RFLP and SSR markers. Theor. Appl. Genet. 106: 1273-1282.

Liu Y, Li Y, Zhou G and Uzokwe N (2010). Development of soybean EST-SSR markers and their use to assess genetic 
diversity in the subgenus Soja. Agr. Sci. China 9: 1423-1429.

Ma J, Wang PW, Yao D, Wang YP, et al. (2011). Single-primer PCR correction: a strategy for false-positive exclusion. Genet. Mol. Res. 10: 150-159.

Sayama T, Nakazaki T, Ishikawa G and Hanada T (2009). QTL analysis of seed-flooding tolerance in soybean (Glycine $\max$ [L.] Merr.). Plant Sci. 176: 514-521.

Wei X, Yang Z, Dong L, Yu H, et al. (2004). SSR evidence for taxonomic position of Weedy Rice'Ludao'. Sci. Agric. Sin. 37: 937-942.

Welsh J and McClelland M (1990). Fingerprinting genomes using PCR with arbitrary primers. Nucleic Acids Res. 18: 7213-7218.

Wen ZX, Zhao TJ, Zhen YZ and Liu SH (2008). Association analysis of agronomic and quality traits with SSR markers in Glycine max and Glycine soja in China: I. Population structure and associated markers. Acta Agron. Sin. 34: 1169-1178.

Williams JG, Kubelik AR, Livak KJ, Rafalski JA, et al. (1990). DNA polymorphisms amplified by arbitrary primers are useful as genetic markers. Nucleic Acids Res. 18: 6531-6535. 